\title{
Application of mineral magnetic concentration measurements as a particle size proxy for urban road deposited sediments
}

\author{
C. J. Crosby ${ }^{1}$, C. A. Booth ${ }^{1}$, A. T. Worsley ${ }^{2}$, M. A. Fullen ${ }^{3}$, \\ D. E. Searle ${ }^{1}$, J. M. Khatib ${ }^{1}$ \& C. M. Winspear ${ }^{1}$ \\ ${ }^{I}$ SEBE, University of Wolverhampton, UK \\ ${ }^{2} N G A S$, Edge Hill University, UK \\ ${ }^{3} S A S$, University of Wolverhampton, $U K$
}

\begin{abstract}
The application of mineral magnetic concentration parameters $\left(\chi_{\mathrm{LF}}, \chi_{\mathrm{ARM}}\right.$ and SIRM) as a potential particle size proxy for urban road deposited sediment collected from Scunthorpe, North Lincolnshire, U.K. has been investigated. Correlation analyses between each magnetic parameter and traditional particle size classes (i.e. sand, silt and clay) and respiratory health related size classes (i.e. $\mathrm{PM}_{10}, \mathrm{PM}_{2.5}$ and $\left.\mathrm{PM}_{1.0}\right)$ are reported. Significant relationships $(p<0.01$; $\mathrm{n}=35$ ) exist between clay content and two of the magnetic concentration parameters $\left(\chi_{\mathrm{ARM}}\right.$ and SIRM). This is also the same for each $\mathrm{PM}_{10}, \mathrm{PM}_{2.5}$ and $\mathrm{PM}_{1.0}$ sizes. Of the three magnetic parameters, $\chi_{\mathrm{ARM}}$ displays the strongest correlation $(\mathrm{r}=0.45 ; p<0.01 ; \mathrm{n}=35)$ values and is the most significant parameter, which is consistent with class sizes of each approach. In doing so, these associations indicate mineral magnetic measurements have considerable potential as a particle size proxy for determining urban roadside particulate matter concentrations. Given the speed, low-cost and sensitivity of the measurements, this suggests magnetic techniques could potentially be used as an alternative and/or complementary exploratory technology for pilot particulate pollution investigations. Furthermore, in certain instances, it could be useful for examining linkages between respiratory health and particulate pollution and vehicle emissions.
\end{abstract}

Keywords: environmental magnetism, particle size, urban street dust, built environment, epidemiology, public health. 


\section{Introduction}

Sediments within urban environments originate from a wide range of sources, both natural and anthropogenic [1]. Numerous studies [2,3] have shown that street sediment is composed of a wide range of particle sizes, commonly biased towards coarse material. That said, the descriptive term of street dust is not always appropriate and, as a consequence, road-deposited sediment (RDS) is a more preferable terminology for studies of urban particulate matter (PM) $[4,5]$.

Urban PM pollution continues to be intensively studied because the finest sediment particles can exert a potentially harmful influence on public health, especially those susceptible to respiratory illness [6]. McConnell [7] found strong linkages with child residence near to major sources and an associated risk of asthma (95\%) due to road traffic sources. Maher [8] analyzed PM on tree leaves at different heights, which showed that metal-rich particulate pollution concentrations are highest at $\sim 0.3 \mathrm{~m}$ (i.e. small child height) and at $1.5-2 \mathrm{~m}$ (adult head height) above ground level. Infant exposure to air pollution is a special concern because their immune system and lungs are not fully developed when exposure begins, raising the possibility of different responses to those seen in adults [6]. It is customary for air quality studies to analyse particulates of two size fractions; the coarse fraction $\mathrm{PM}_{10}\left(d_{\mathrm{a}} \leq 10 \mu \mathrm{m}\right)$ and fine fraction $\mathrm{PM}_{2.5}$ $\left(d_{\mathrm{a}} \leq 2.5 \mu \mathrm{m}\right)$. More recently, the adopted changeover point between coarse and fine particles occurs at $\operatorname{PM}_{1.0}\left(d_{\mathrm{a}} \leq 1.0 \mu \mathrm{m}\right)$. The success or failure of the respiratory defence systems partly depends upon the size of the particulates inhaled and the depth of their penetration into the respiratory tract [9]. A recent assessment by the 'EPAQS' [10] concluded that both coarse and fine fractions represent health risks, although the disease outcomes may differ for the two size fractions [11].

Since 1997, UK local authorities have been reviewing and assessing air quality in their area, to work towards meeting the national air quality objectives. There are over 1500 monitoring sites across the UK, which monitor air quality (monitoring $\mathrm{PM}_{10}$ concentrations, amongst those of several other pollutant measurements). In 2003 the UK Government set lower limits for fine particle concentrations, which need to be reached by 2010. Currently, the main source of airborne fine particulates in the UK is road traffic emissions [12]. However, it is estimated, by 2010, that road transport emissions of fine particles will fall by two-thirds of those a decade ago [13]. Moreover, the European Commission has proposed that the legislation on particulate matter should be supplemented by setting a limit value of $35 \mu \mathrm{g} / \mathrm{m}^{3}$ for $\mathrm{PM}_{2.5}$ particles and an interim reduction target of $20 \%$ to be attained between 2010 and 2020 [12]. Assessment of the extent and severity of urban dust concentrations requires thorough investigation before Air Quality Management Plans and remediation can be instigated, which means that there is scope for new PM monitoring technologies.

It is, therefore, timely for innovative PM technologies to be considered as an alternative, or in tandem, to those already employed to determine $\mathrm{PM}_{2.5}$ and $\mathrm{PM}_{10}$ concentrations. Ideally, they need to be rapid, reliable and inexpensive. However, to assess the suitability of any analytical technique as an efficient 
particle size proxy it is necessary that the nature of the relationship between the proposed parameters and particle size follow a predictable pattern. Many studies have previously explored relationships between mineral magnetic measurements and the physico-chemical properties of soils, sediments and dusts. Based on these investigations, from host environmental settings (e.g. soils, deserts, glacial, lakes, coastal and marine), magnetic measurements have previously been identified as a suitable proxy for geochemical, radioactivity, organic matter content and particle size data [14-17].

Two hypotheses are tested here: Firstly, the extent to which particular magnetic concentration parameters can be used as a particle size proxy for urban RDS; and, secondly, whether theses data associations follow the predictable trends of other environmental studies.

\section{Case study}

Air quality $\mathrm{PM}_{10}$ measurements for the UK reveal a host of towns and cities that exceed the permitted European concentration levels [18]. This includes the town of Scunthorpe, which is the administrative centre of North Lincolnshire and home to an estimated resident population of $\sim 72,500$. It was founded in Roman times but the town mainly grew, from 1859 onwards, when local iron ore was discovered and mined. This resulted in the development of a nearby iron and steel industry and a concomitant rapid population growth. Today, the steel industry (Corus, an Indian-owned firm) still remains (on the eastern side of the town (national grid reference: SE 911 104)) and is a major employer in the town (4,500 personnel in 2008). Nationally, this industry is acknowledged to be a potential major contributor to poor air quality [19]. As a_consequence, the local authority (North Lincolnshire council) operates a series of air sampling stations, which are used to monitor levels of particulates in the area (Figure 1). These sources are mainly industry and traffic related [19].

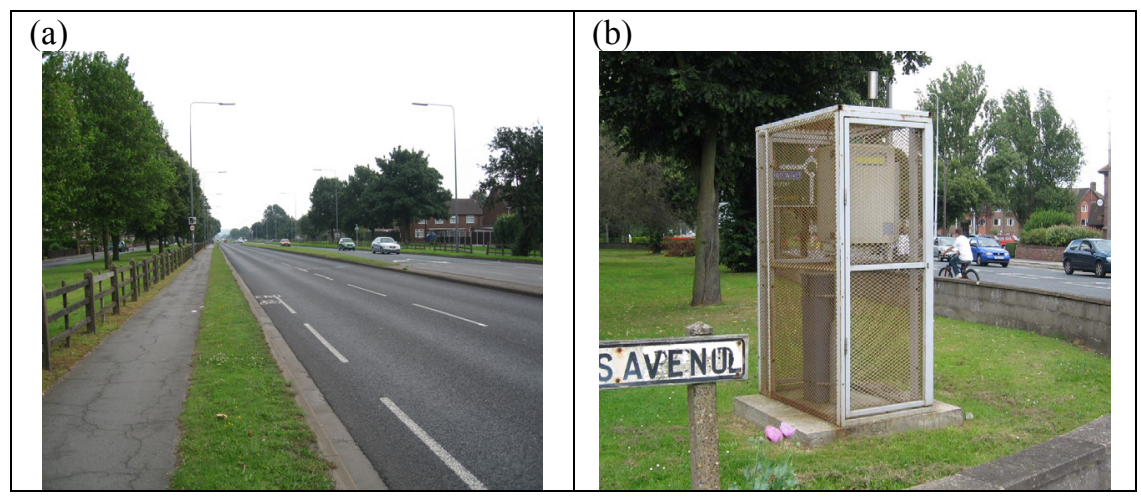

Figure 1: Scunthorpe scenes: (a) the main A18 dual-carriageway road facing west (NGR: SE 902 092) and (b) the air sampling station near to the town centre crossroads (NGR: SE 891 108). 
The heart of the town is close to the crossroads of the main A18 road (Figure 1) (Brigg is $\sim 12 \mathrm{~km}$ to the east and Hatfield is $\sim 24 \mathrm{~km}$ to the west) and the A159 road (Figure 1(b) (Gainsborough is $\sim 23 \mathrm{~km}$ to the south). The limits of the town are constrained b)y the M180 and the M181 motorways (highways) to the south and west, respectively.

\section{Materials and methods}

RDS samples were collected from both main and residential roads within the town of Scunthorpe (July 2008).

\subsection{Sample collection and preparation}

RDS were collected from the surface of roads, gutters and pavements (sidewalks) of the town's roads. Typically, 30-50 g sediment samples were collected (from $\sim 1 \mathrm{~m}^{2}$ ) by sweeping with a small hand-held fine-bristle brush. Sediment was then transferred to clean, pre-labelled, self-seal, airtight plastic bags. In the laboratory, samples were visibly screened to remove macroscopic traces of hair, animal and plant matter [20].

\subsection{Mineral magnetic measurements}

All samples were subjected to the same preparation and analysis procedure. Samples were dried at room temperature $\left(<40^{\circ} \mathrm{C}\right)$, weighed, packed into $10 \mathrm{ml}$ plastic pots and immobilized with clean sponge foam and tape prior to analysis. Initial, low-field, mass-specific, magnetic susceptibility $(\chi)$ was measured using a Bartington (Oxford, England) MS2 susceptibility meter. By using a MS2B sensor, low frequency susceptibility was measured $\left(\chi_{\mathrm{LF}}\right)$. Anhysteretic Remanence Magnetisation (ARM) was induced with a peak alternating field of $100 \mathrm{mT}$ and small steady biasing field of $0.04 \mathrm{mT}$ using a Molspin (Newcastleupon-Tyne, England) A.F. demagnetiser. The resultant remanence created within the samples was measured using a Molspin 1A magnetometer and the values converted to give the mass specific susceptibility of ARM $\left(\chi_{\text {ARM }}\right)$. The samples were then demagnetized to remove the induced ARM and exposed to a series of successively larger field sizes up to a maximum 'saturation' field of $1000 \mathrm{mT}$, followed by a series of successively larger fields in the opposite direction (backfields), generated by two Molspin pulse magnetisers (0-100 and 0-1000 $\mathrm{mT}$ ). After each 'forward' and 'reverse' field, sample isothermal remanent magnetisation (IRM) was measured using the magnetometer [21].

\subsection{Laser diffraction measurements}

All samples were subjected to the same textural preparation and analysis procedure, using sieving (2000 $\mu \mathrm{m}$ aperture) followed by laser diffraction analysis. Low Angle Laser Light Scattering (LALLS), using a Malvern (Malvern, England) Mastersizer Long-bed X with a MSX17 sample presentation 
unit, enabled rapid measurement of particle sizes within the 0.1-2000 $\mu \mathrm{m}$ range. Macroscopic traces of organic matter were removed from representative subsamples before being dampened by the dropwise addition of a standard chemical solution $\left(40 \mathrm{~g} / \mathrm{l}\right.$ solution of sodium hexametaphosphate $\left(\left(\mathrm{NaPO}_{3}\right)_{6}\right)$ in distilled water) to help disperse aggregates. To ensure complete disaggregation, each slurry was then subjected to ultrasonic dispersion in a Malvern MSX17 sample presentation unit. For greater precision, the mean of five replicate analyses was measured with a mixed refractive indices presentation setting. A standard range of textural parameters was calculated, including the percentage of sand, silt and clay class sizes and their sub-intervals. The Malvern instrumentation was regularly calibrated using latex beads of known size [22].

\section{Results}

Particle size data $(\mathrm{n}=35)$ indicates samples are dominated by sand $(\sim 77 \%)$, silt $(\sim 19 \%)$ and clay $(\sim 3 \%)$, in respective orders (Table 1). From a respiratory-health perspective, $\mathrm{PM}_{10}$ grains represent $\sim 8 \%, \mathrm{PM}_{2.5} \sim 3 \%$ and $\mathrm{PM}_{1.0} \sim 2 \%$ of the sediments. Once suspended, particles $<10 \mu \mathrm{m}$ are able to remain airborne for hours or days and, in some cases, even weeks [11]. Therefore, the presence of PM of these sizes on pavement surfaces indicates either the particles have not been disturbed recently or they have only just settled-out. That said, since the town centre pavements normally receive frequent and heavy foot-traffic, it is assumed the time of sampling (04:00 - 08:00) and the weather conditions (warm, dry and still) have permitted sizeable PM accumulations.

Table 1: $\quad$ Summary particle size properties of urban RDS: (a) traditional sediment size fractions and (b) respiratory health-related size fractions ( $\mathrm{n}=35$ samples).

\begin{tabular}{|l|c|c|c|c|}
\hline (a) & $\begin{array}{c}\text { Mean } \\
(\mathbf{\%})\end{array}$ & $\begin{array}{c}\text { Maximum } \\
(\mathbf{\%})\end{array}$ & $\begin{array}{c}\text { Minimum } \\
(\mathbf{\%})\end{array}$ & $\begin{array}{c}\text { Standard } \\
\text { Deviation }\end{array}$ \\
\hline Sand $(63-2000 \mu \mathrm{m})$ & 77.23 & 88.18 & 56.38 & 7.80 \\
\hline Silt $(2-63 \mu \mathrm{m})$ & 19.86 & 39.95 & 9.36 & 7.42 \\
\hline Clay $(<2 \mu \mathrm{m})$ & 2.89 & 7.01 & 1.04 & 1.58 \\
\hline (b) & $\begin{array}{c}\text { Mean } \\
(\%)\end{array}$ & $\begin{array}{c}\text { Maximum } \\
(\mathbf{\%})\end{array}$ & $\begin{array}{c}\text { Minimum } \\
\mathbf{( \% )}\end{array}$ & $\begin{array}{c}\text { Standard } \\
\text { Deviation }\end{array}$ \\
\hline$<\mathrm{PM}_{10}$ & 8.06 & 16.18 & 3.21 & 3.65 \\
\hline$<\mathrm{PM}_{2.5}$ & 3.35 & 7.76 & 1.40 & 1.72 \\
\hline$<\mathrm{PM}_{1.0}$ & 1.92 & 5.23 & 0.73 & 1.20 \\
\hline
\end{tabular}

Table 2 summarizes the mineral magnetic characteristics. $\chi_{\mathrm{LF}}$ is roughly proportional to the concentration of ferrimagnetic minerals within the sample, although in materials with little or no ferrimagnetic component and a relatively large antiferromagnetic component, the latter may dominate the signal. $\chi_{\text {ARM }}$ is particularly sensitive to the concentration of magnetic grains of stable single 
domain size, e.g. $\sim 0.03-0.06 \mu \mathrm{m}$. SIRM is related to concentrations of all remanence-carrying minerals in the sample, but is also dependent upon the assemblage of mineral types and their magnetic grain size. These data indicate the samples contain moderate to very high magnetic concentrations. Yet, compared with previous urban magneto-dust studies, the mean values are more than double those of Liverpool $\left(23.7 \times 10^{-7} \mathrm{~m}^{3} \mathrm{~kg}^{-1}\right)$ [23] and Shanghai $\left(29.9 \times 10^{-7} \mathrm{~m}^{3} \mathrm{~kg}^{-1}\right)[24]$.

Table 2: $\quad$ Summary magnetic properties of urban $\operatorname{RDS}(\mathrm{n}=35$ samples).

\begin{tabular}{|l|l|c|c|c|c|}
\hline & Units & Mean & Maximum & Minimum & $\begin{array}{c}\text { Standard } \\
\text { Deviation }\end{array}$ \\
\hline$\chi_{\text {LF }}$ & $10^{-7} \mathrm{~m}^{3} \mathrm{~kg}^{-1}$ & 60.86 & 123.34 & 20.87 & 28.32 \\
\hline$\chi_{\text {ARM }}$ & $10^{-7} \mathrm{~m}^{3} \mathrm{~kg}^{-1}$ & 0.180 & 1.09 & 0.03 & 0.21 \\
\hline SIRM & $10^{-5} \mathrm{Am}^{2} \mathrm{~kg}^{-1}$ & 1270.39 & 9686.42 & 194.58 & 1682.48 \\
\hline
\end{tabular}

Table 3 shows the Pearson's correlation coefficient values $(r)$ between the mineral magnetic concentration parameters and particle size parameters, grouped according to traditional sediment size fractions and respiratory health-related size fractions. Significant relationships $(p<0.01 ; \mathrm{n}=35)$ exist between clay content and both the $\chi_{\text {ARM }}$ and SIRM magnetic concentration parameters. This is also the same for with all the respiratory class sizes of the finer fraction $<\mathrm{PM}_{10}(p<0.01)$. Therefore, this indicates that $\chi_{\mathrm{ARM}}$ and SIRM magnetic concentration parameters could be used as a particle size proxy, particularly if the kinship is required with particle sizes $\mathrm{PM}_{1.0}, \mathrm{PM}_{2.5}$ or $\mathrm{PM}_{10}$. However, it is also noteworthy that $\chi_{\mathrm{LF}}$ displays no significant relationship throughout all size fractions.

Table 3: Pearson's correlation coefficients (r) between mineral magnetic concentration and particle size parameters for urban RDS: (a) traditional sediment size fractions and (b) respiratory healthrelated size fractions $(\mathrm{n}=35$ samples $)$.

\begin{tabular}{|l|c|c|c|}
\hline (a) & $\begin{array}{c}\text { Clay } \\
<\mathbf{2} \boldsymbol{\mu m}\end{array}$ & $\begin{array}{c}\text { Silt } \\
\mathbf{2 - 6 3} \boldsymbol{\mu m}\end{array}$ & $\begin{array}{c}\text { Sand } \\
\mathbf{6 3 - 2 0 0 0} \boldsymbol{\mu m}\end{array}$ \\
\hline$\chi_{\mathrm{LF}}$ & 0.30 & -0.12 & 0.05 \\
\hline$\chi_{\mathrm{ARM}}$ & $0.45^{* *}$ & 0.0 & -0.09 \\
\hline SIRM & $0.43^{* *}$ & 0.05 & -0.13 \\
\hline (b) & $<\mathbf{P M}_{\mathbf{1 . 0}}$ & $<\mathbf{P M}_{\mathbf{2 . 5}}$ & $<\mathbf{P M}_{\mathbf{1 0}}$ \\
\hline$\chi_{\mathrm{LF}}$ & 0.31 & 0.29 & 0.26 \\
\hline$\chi_{\mathrm{ARM}}$ & $0.42^{* *}$ & $0.45^{* *}$ & $0.44^{* *}$ \\
\hline SIRM & $0.40^{*}$ & $0.43^{* *}$ & $0.43^{* *}$ \\
\hline
\end{tabular}

Note: Significance levels: $p<0.05=* ; p<0.01=* *$. 


\section{Discussion}

Previous magnetic studies have noted significant correlations between $\chi_{\mathrm{LF}}, \chi_{\mathrm{ARM}}$, SIRM and particle size. To date, Oldfield et al. [25] has identified that anhysteretic remanent magnetisation (ARM) measurements can be used to reflect the concentration of fine-grained magnetite $(<0.1 \mu \mathrm{m})$ in the clay fraction and low-frequency magnetic susceptibility $\left(\chi_{\mathrm{LF}}\right)$ measurements can be used to infer the presence of coarser multi-domain magnetite $(>1.0 \mu \mathrm{m})$ in sands and coarse silts. Clifton et al. [15] found $\chi_{\mathrm{LF}}$ was strongly associated with sands and medium silts, susceptibility of ARM $\left(\chi_{\mathrm{ARM}}\right)$ was strongly associated with clay and fine silts, and saturated isothermal remanent magnetisation (SIRM) was strongly associated with very fine to medium silts. Zhang et al. [26] suggested that both percentage frequency-dependent magnetic susceptibility $\left(\chi_{\mathrm{FD} \%}\right)$ and $\chi_{\text {ARM }}$ can be used as a proxy for clay content. The potential application of mineral magnetic measurements as a proxy for urban PM was highlighted by Booth et al. [17], who noted that $\chi_{\mathrm{LF}}, \chi_{\mathrm{ARM}}$ and SIRM parameters correlate with all class sizes. Moreover, Booth et al. [16] suggested $\chi_{\text {LF }}, \chi_{\text {ARM }}$ and SIRM have potential as a particle size proxy for several sedimentary environments, but highlights the importance of fully determining the nature of the relationship between sediment particle size and magnetic properties before applying mineral magnetic data as a size proxy. More recently, this was further explored by Booth et al. [27] who discussed potential problems of employing this technology.

These studies illustrate sand correlated negatively with $\chi_{\mathrm{LF}}(\mathrm{r}=-0.94), \chi_{\mathrm{ARM}}$ $(\mathrm{r}=-0.96)$ and SIRM $(\mathrm{r}=-0.91)$; silt correlated positively with $\chi_{\mathrm{LF}}(\mathrm{r}=0.96)$, $\chi_{\text {ARM }}(\mathrm{r}=0.96)$ and SIRM $(\mathrm{r}=0.96)$; and clay correlated positively with $\chi_{\mathrm{LF}}$ $(\mathrm{r}=0.82), \chi_{\text {ARM }}(\mathrm{r}=0.94)$ and $\operatorname{SIRM}(\mathrm{r}=0.81)$. They also illustrate $\mathrm{PM}_{10}$ correlated positively with $\chi_{\mathrm{LF}}(\mathrm{r}=0.69) ; \mathrm{PM}_{2.5}$ correlated positively with $\chi_{\mathrm{LF}}$ $(\mathrm{r}=0.70), \chi_{\text {ARM }}(\mathrm{r}=0.30)$ and SIRM $(\mathrm{r}=0.33)$; and $\mathrm{PM}_{1.0}$ correlated positively with $\chi_{\text {LF }}(r=0.66), \chi_{\text {ARM }}(r=0.41)$ and SIRM $(r=0.32)$. When data presented here are compared to these earlier investigations, it is apparent that the trends observed are mostly similar to previous studies (e.g. clay and $\chi_{\text {ARM }}(r=0.45)$ and SIRM $(\mathrm{r}=0.43) ; \mathrm{PM}_{10}, \mathrm{PM}_{2.5}$ and $\mathrm{PM}_{1.0}$ with $\chi_{\text {ARM }}(\mathrm{r}=0.45)$ and SIRM $(\mathrm{r}=0.43))$ but, unlike other work, $\chi_{\mathrm{LF}}$ displays no significant relationship. The magneto-associations with each of the traditional sediment class sizes highlights the potential use of mineral magnetic data as a means of normalizing compositional analytical data (i.e. geochemical) for particle size effects.

The significant correlations between the magnetic parameters and the respiratory-health related size classes is perhaps of greater importance, because this highlights the technique as a possible alternative PM monitoring tool, which could be linked to both health and pollution studies. Given the combination of low-cost and sensitivity of the method, it can be argued that mineral magnetic measurements have considerable potential to act as a reliable particle size proxy. The method is also rapid; bulk samples require little preparation and individual measurements of magnetic susceptibility $\left(\chi_{\mathrm{LF}}\right)$ can be made in $\sim 1$ minute, in either a laboratory or field setting. Therefore, it is feasible that mineral magnetic 
measurements could be a dependable and rapid exploratory technology for pilot urban roadside $\mathrm{PM}$ investigations.

\section{Ongoing related work}

This work forms part of a wider investigation extended to other UK towns and cities (Runcorn, Salford, Dumfries, Oswestry, Norwich, Wolverhampton and London), which is attempting to answer the same hypotheses posed in the case study presented in this work. In doing so, it is anticipated it will offer better insights of the reliability of mineral magnetic technologies as an alterative PM monitoring approach.

\section{Further work}

Although not presented here, when the magnetic concentration data for this case study is entered into a GIS and the information presented spatially, it reveals a distinct and noteworthy pattern that illustrates an east-to-west magneto-gradient from low to high concentration values. At this time, it is perceived that this trend can be attributed to emissions from industrial activities on the eastern side of the town and, therefore, proffers that magnetic technologies may be a suitable technology for establishing sources linkages or distinguishing between vehicular and industrial pollution signals of urban sediments.

\section{Conclusions}

Analyses indicate magnetic concentration parameters could be reliably employed as a suitable particle size proxy for urban RDS. Of the three magnetic parameters, $\chi_{\mathrm{ARM}}$ and SIRM has the strongest and most significant correlation values $(\mathrm{P}<0.01)$ with all respiratory class sizes $<10 \mu \mathrm{m}$. In most cases, these data associations follow the predictable trends of other environmental studies. Therefore, given the speed, low-cost and sensitivity of the measurements, this suggests magnetic techniques could be used as a rapid alternative exploratory technology for pilot particulate pollution investigations.

\section{Acknowledgements}

All authors thank the School of Applied Sciences for unlimited access to analytical facilities. The first author also gratefully acknowledges the receipt of a doctoral studentship hosted by the School of Engineering and the Built Environment at the University of Wolverhampton.

\section{References}

[1] Robertson, D.J., Taylor, K.G., \& Hoon, S.R. 2003. Geochemical and mineral magnetic characterisation of urban sediment particulates, Manchester, UK Applied Geochemistry, 18, 269-282. 
[2] Lau, W.M., \& Wong, M.H. 1983. The effect of particle size and different extractants on the contents of heavy metals in roadside dusts. Environmental Research, 31, 229-242.

[3] Fergusson, J.E., \& Ryan, D.E. 1984. The elemental composition of street dust from large and small urban areas related to city type, source and particle size. Science of the Total Environment, 34, 101-116

[4] Herngren, L., Goonetilleke, A., \& Ayoko, G.A. 2006. Analysis of heavy metals in road-deposited sediments. Analytica Chimica Acta, 571, 270278.

[5] Sutherland, R.A. 2003. Lead in grain size fractions of road-deposited sediment. Environmental Pollution, 121, 229-237.

[6] Schwartz, J. 2004. Air pollution and children's health. Pediatrics, 113, 1137-1043.

[7] McConnell, R., Berhane, K., Yao, L., Jerrett, M., Lurmann, F., Gilliland, F., Kunzli, N., Gauderman, J., Avol, E., Thomas, D., \& Peters, J. 2006. Traffic, susceptibility and childhood asthma. Environmental Health Perspectives, 114, 766-772.

[8] Maher, B.A., Moore, C., \& Matzka, J. 2008. Spatial variation in vehicle derived metal pollution identified by magnetic and elemental analysis of roadside tree leaves. Atmospheric Environment, 42. 364-373.

[9] Yeh, H.C., G. M. Schum \& Duggan, M.T. 1979. Anatomical models of the tracheobronchial and pulmonary regions of the rat. Anat. Rev. 195, 483492.

[10] EPAQS. 2001 Airborne particles, Expert Panel on Air Quality Standards, London: HMSO.

[11] Harrison, R.M. 2004. Key pollutants - airborne particles. Science of the Total Environment, 334, 3-8.

[12] www.defra.gov.uk/environment/airquality/aqeg

[13] www.environment-agency.gov.uk

[14] Bonnett, P.J.P., Appleby, P.G., \& Oldfield, F. 1998. Radionuclides in coastal and estuarine sediments from Wirral and Lancashire. Science of the Total Environment, 70, 215-236.

[15] Clifton, J., McDonald, P., Plater, A., \& Oldfield, F. 1999. Derivation of a grain-size proxy to aid the modelling and prediction of radionuclide activity in saltmarshes and mud flats of the Eastern Irish Sea. Estuarine, Coastal and Shelf Science, 48, 511-518.

[16] Booth, C.A., Walden, J., Neal, A., \& Smith, J.P. 2005. Use of mineral magnetic concentration data as a particle size proxy: a case study using marine, estuarine and fluvial sediments in the Carmarthen Bay area, South Wales, U.K. Science of the Total Environment, 347, 241-253.

[17] Booth, C.A., Winspear, C.M., Fullen, M.A., Worsley, A.T., Power, A.L., \& Holden, V.J.C. 2007. A pilot investigation into the potential of mineral magnetic measurements as a proxy for urban roadside particulate pollution. In: Air Pollution XV, (Editors) C.A. Borrego \& C.A Brebbia, WIT Press, 391-400.

[18] www.bv-aurnsiteinfo.co.uk 
[19] www.northlincs.gov.uk

[20] Shilton, V.F., Booth, C.A., Giess, P., Mitchell, D.J., \& Williams, C.D. 2005. Magnetic properties of urban street dust and its relationship to organic matter content in the West Midlands, U.K. Atmospheric Environment, 39, 3651-3659.

[21] Booth, C.A., Walden, J., Neal, A., Smith, J.P., \& Morgan, E. 2004. A comparison of inter-unit, intra-site and intra-sample variability in environmental magnetic data: an example based on the Gwendraeth Estuary, South Wales, U.K. Journal of Coastal Research, 20, 808-813.

[22] Booth, C.A., Fullen, M.A., Smith, J.P., Hallett, M.D., Walden, J., Harris, J., \& Holland, K. 2005. Magnetic properties of agricultural topsoils of the Isle of Man: their characterisation and discrimination by factor analysis. Communications in Soil Science \& Plant Analysis, 36, 1241-1262.

[23] Xie, S., Dearing, J.A., \& Bloemandal, J. 2000. The organic matter content of street dust in Liverpool, UK and its association with dust magnetic properties. Atmospheric Environment, 34, 269-275.

[24] Shu, J., Dearing, J.A., Morse, A.P., Yu, L., \& Yuan, N. 2001. Determining the source of atmospheric particles in Shanghai, China, from magnetic geochemical properties. Atmospheric Environment, 35, 2615 2625 .

[25] Oldfield, F., Richardson, N., Appleby, P.G., \& Yu, L. 1993. ${ }^{241}$ Am and ${ }^{137} \mathrm{Cs}$ activity in fine-grained saltmarsh sediments from parts of the N.E. Irish Sea shoreline. Journal of Environmental Radioactivity, 19, 1-24.

[26] Zhang, W., Yu, L., \& Hutchinson, S.M. 2001. Diagenesis of magnetic minerals in the intertidal sediments of the Yangtze Estuary, China, and its environmental significance. Science of the Total Environment, 266, 160175.

[27] Booth, C.A., Fullen, M.A., Walden, J., Worsely, A.T., Marcinkinos, S., \& Coker, A.O. 2008. Problems and potential of mineral magnetic measurements as a particle size proxy: a case study using Manx topsoils. Journal of Environmental Engineering and Landscape Management, 3, 151-157. 